\title{
Development of Acute Edema Following Cerebral Hypoxia-Ischemia in Neonatal Compared with Juvenile Rats Using Magnetic Resonance Imaging
}

\author{
MIN QIAO, PETER LATTA, SHUZHEN MENG, BOGUSLAW TOMANEK, AND URSULA I. TUOR \\ Institute for Biodiagnostics (West), National Research Council of Canada [M.Q., P.L., S.M., B.T., U.I.T.] \\ and Faculty of Medicine, University of Calgary [B.T., U.I.T.], Calgary, Alberta T2N 4N1, Canada
}

\begin{abstract}
ABST
We hypothesized that the evolution of cerebral edema accom-
panying cerebral hypoxia-ischemia is dependent on age and that
such differences would be detectable using magnetic resonance
imaging methods. Thus we examined in immature and juvenile
rats the relationship between hypoxic-ischemic changes in $\mathrm{T}_{1}$
and $\mathrm{T}_{2}$ and the alterations in brain water content, as assessed by
differences in tissue wet-dry weights. One- and 4 -wk-old rats
were anesthetized and subjected to unilateral carotid artery oc-
clusion and subsequent exposure to hypoxia (8\% oxygen). $\mathrm{T}_{1}$ and
$\mathrm{T}_{2}$ maps were acquired at $9.4 \mathrm{~T}$, and then brain water content was
measured in sham controls or in hypoxic-ischemic animals be-
fore, during, and 1 or $24 \mathrm{~h}$ after hypoxia-ischemia. In sham
controls, $\mathrm{T}_{1}$, $\mathrm{T}_{2}$, and proton density decreased with increasing
age, corresponding to an ontogenic decrease in water content. In
1 -wk-old rats, increases in $\mathrm{T}_{1}$ and $\mathrm{T}_{2}$ were observed during and
at 1 and $24 \mathrm{~h}$ after hypoxia-ischemia, corresponding to elevations
\end{abstract}
in water content. In 4-wk-old rats, $\mathrm{T}_{1}$ and water content increased during and at 1 and $24 \mathrm{~h}$ after hypoxia-ischemia whereas $\mathrm{T}_{2}$ was not increased until $24 \mathrm{~h}$ after hypoxia-ischemia. Regression analysis showed that $T_{1}$ correlated better with total water content than $\mathrm{T}_{2}$. In both immature and older brain, an increase in total brain water develops acutely and persists after an episode of cerebral hypoxia-ischemia, and $T_{1}$ imaging detects this change better than $T_{2}$. Hypoxic-ischemic changes in $T_{2}$ are age dependent, reflecting other physicochemical changes of water in the tissue than water content alone. (Pediatr Res 55: 101-106, 2004)
HI, hypoxia-ischemia
MR, magnetic resonance
BBB, blood-brain barrier

Abbreviations

Cerebral ischemia produces a tissue edema consisting of a combination of intracellular and extracellular water accumulation within the tissue. The edema associated with ischemia has been assessed frequently using one or more noninvasive MR imaging techniques (1) in which the contrast has been based primarily on regional differences in proton density, spin-lattice $\left(\mathrm{T}_{1}\right)$, or spin-spin $\left(\mathrm{T}_{2}\right)$ proton relaxation times. Considering the fact that the majority of protons within the brain are found in water molecules, changes in intensity in $T_{1}$ - and $T_{2}$-weighted images have often been interpreted to represent edema and have been used to monitor its progression under various pathologic states including cerebral ischemia and brain trauma (2). However, the actual changes in water content or the biophysical properties of the tissue that underlie many of the MR imaging changes remain poorly understood. Indeed, those stud-

Received February 6, 2003; accepted July 15, 2003.

Correspondence: Ursula I. Tuor, Ph.D., Institute for Biodiagnostics (West), National Research Council of Canada, B153, 3330 Hospital Drive NW, Calgary, Alberta T2N 4N1, Canada; e-mail: Ursula.Tuor@nrc-cnrc.gc.ca

Supported by the Canadian Institutes for Health Research.

DOI: 10.1203/01.PDR.0000100477.59081.FE ies measuring ontogenic or pathologic changes in tissue water content have reported a range of poor, mild, and good correlations between water content and $\mathrm{MR}$ variables such as $\mathrm{T}_{2}$ and $\mathrm{T}_{1}$ (3-12). The majority of such studies have not examined the correlation of the changes in MR relaxation variables with the evolution of the pathologic edema as a function of time, and even fewer have investigated directly the relationship between changes in MR variables and the edema resulting from a cerebral HI insult. Recently, we reported that there are agedependent changes in $\mathrm{T}_{2}$ after an episode of transient hypoxia in immature rats with unilateral carotid artery occlusion. In this model of hypoxia plus incomplete cerebral ischemia, changes in $\mathrm{T}_{2}$ correlate better to a combined alteration in water content and protein extravasation than to either altered water content or a disruption in the BBB alone (13). Although in this study we did not investigate changes in $T_{1}$, such changes have the potential for providing an alternative and perhaps preferred measure of edema. We hypothesized that the $T_{1}$ changes detected in edematous tissue would be affected by the maturity of brain and that $T_{1}$ would correlate better with water content than $T_{2}$. To test this, we investigated the relationship between 
water content and the temporal changes in $\mathrm{T}_{1}, \mathrm{~T}_{2}$, and proton density with MR techniques during and after a cerebral $\mathrm{HI}$ insult in 1- and 4-wk-old brain in which the maturity of the rat brain at these ages corresponds roughly to newborn and juvenile (prepuberty) stages of human development, respectively (14).

\section{METHODS}

Model of cerebral HI. Pregnant Wistar rats were obtained from Charles River Laboratories (Montreal, Canada) and gave birth approximately $1 \mathrm{wk}$ after their arrival, after which the litter was culled to 9 to 10 pups. All animals were treated in accordance with the guidelines provided by the Canadian Council on Animal Care, and experiments were approved by the local animal care committee. Animals were assigned to experiments to be performed at one of two ages: 1 or $4 \mathrm{wk}$. Cerebral HI was produced as described previously and involved permanent ligation of the right carotid artery with subsequent exposure to an episode of hypoxia ( $8 \%$ oxygen in nitrogen) (15). In this model of cerebral HI, ligation of the carotid artery alone does not result in ischemia because of collateral blood flow via the circle of Willis. During HI, there is a transient episode of incomplete ischemia produced within the hemisphere ipsilateral to the occlusion (16).

In each animal, the right common carotid artery was ligated and severed under isoflurane (2.5\%) anesthesia. The incision site was closed, and saline solution $(0.1 \mathrm{~mL} / 10 \mathrm{~g}$, i.p.) was injected to compensate for any fluid losses during surgery. In the sham-control group, the carotid artery was isolated but not ligated. After surgery, the rats were returned to the cage with the mother for $1-2 \mathrm{~h}$ of recovery from the anesthesia. Rats were then exposed to hypoxia by spontaneously breathing humidified $8 \%$ oxygen in $92 \%$ nitrogen for a duration of $1.5 \mathrm{~h}$ for 1-wk-old rats or $30 \mathrm{~min}$ for 4-wk-old rats, thereby producing a cerebral infarct of similar size (17). Body temperature was maintained at $37.0^{\circ}-37.5^{\circ} \mathrm{C}$ during hypoxia with a heating lamp and circulating water blanket.

MR imaging. $\mathrm{T}_{1}$ and $\mathrm{T}_{2}$ maps were obtained with a 9.4-T, 21-cm horizontal bore magnet (Magnex, Yarton, U.K.) equipped with an Avance Bruker console (Bruker, Ettlingen, Germany). The animals were anesthetized with isoflurane (0.5$1.25 \%$ ) and placed in a chamber designed to fit the bore of the magnet. In 1-wk-old rats, the head was restrained with a foam-lined head holder, and in 4-wk-old rats the head was restrained with ear pins and an incisor bar within a quadrature rf coil. Respiration rate was monitored continuously while animals were in the magnet. Within each age group $(n=20)$, images were acquired in sham controls $(n=5)$ or HI rats immediately before $\mathrm{HI}(n=15$, all the $\mathrm{HI}$ rats were imaged before $\mathrm{HI})$, during $\mathrm{HI}(n=5)$, at $1 \mathrm{~h}(n=5)$, or $24 \mathrm{~h}(n=5)$ after HI. At the end of imaging at each time point the rats were killed for the assessment of water content. $\mathrm{T}_{2}$ maps were determined using a spin-echo multiecho imaging sequence consisting of slice-selective $90^{\circ}$ and $180^{\circ}$ sinc pulses with a length of $4 \mathrm{~ms}$ and $3 \mathrm{~ms}$, respectively. The $\mathrm{T}_{2}$ map was obtained from an eight-echo train with $20 \mathrm{~ms}$ of echo spacing and repetition time (TR) of $1200 \mathrm{~ms}$ within a slice at the level of striatum having a thickness of $1 \mathrm{~mm}$ for 1 -wk-old and 1.5 $\mathrm{mm}$ for 4-wk-old rats. The field of view was $3 \mathrm{~cm} \times 3 \mathrm{~cm}$ and the data matrix was $256 \times 128$. The signal intensity within each voxel and at each echo was used to determine the $T_{2}$ relaxation times using a nonlinear least squares fitting algorithm. $\mathrm{T}_{2}$-weighted images were acquired at the third echo (TE $=60 \mathrm{~ms}) . \mathrm{T}_{1}$ maps were acquired with an inversion-recovery Snapshot-FLASH imaging technique (inversion Sinc pulse and excitation Gauss pulse with a length of $5 \mathrm{~ms}$ and $1 \mathrm{~ms}$, respectively): $\mathrm{TR}=3.55 \mathrm{~ms}, \mathrm{TE}=2.1 \mathrm{~ms}$, increasing time of inversion (TI) delays of 234, 503, 831, 1233, 1751, 2480, 3728, $9226 \mathrm{~ms}$ between the inversion pulse and the imaging sequence, a field of view of $3 \mathrm{~cm} \times 3 \mathrm{~cm}$, slice thickness of 1.5 $\mathrm{mm}$, and a data matrix of $128 \times 128 . \mathrm{T}_{1}$-weighted images were obtained at a TI delay of $1233 \mathrm{~ms}$. Proton density was estimated from the $T_{1}$ fit of the data (18) and normalized to the $T_{1}$ of water within tubing adjacent to the head of the rat. $T_{1}, T_{2}$, and proton density were measured from ipsilateral and contralateral parietal cortex using image analysis software (Marevisi, Institute for Biodiagnostics, National Research Council of Canada) (19).

Assessment of changes in brain water. Brain water was determined in 201 -wk-old and 204 -wk-old rats by measuring the percentage of the difference in wet and dry weights of the brain samples (13). After the last set of images were obtained within each age group, subgroups of rats were euthanized consisting of sham-control animals $(n=5)$ or HI animals euthanized at one of three times: during HI $(n=5)$, at $1 \mathrm{~h}(n$ $=5)$, or at $24 \mathrm{~h}(n=5)$ after HI. The animals were injected with pentobarbital $(120 \mathrm{mg} / \mathrm{kg})$, the brain was removed, and samples of forebrain containing the striatum from the ipsilateral and contralateral hemispheres were weighed and dried in an oven at $100^{\circ} \mathrm{C}$ for $4-5 \mathrm{~d}$.

Statistical analysis. Grouped data (e.g. ipsilateral and contralateral $\mathrm{T}_{1}, \mathrm{~T}_{2}$, and water content) are presented as their mean $\pm \mathrm{SD}$. A paired $t$ test was used to compare ipsilateralcontralateral differences. The mean ratios of values obtained from the ipsilateral versus contralateral hemisphere at variable times from different animals during and after HI were compared against the control group with an ANOVA followed by a Newman-Keuls test (Statistica; StatSoft, Tulsa, OK, U.S.A.). Differences were considered significant at $p<0.05$. A least squares regression analysis was used to analyze the correlation of alterations in brain water compared with changes in $T_{1}$ or $T_{2}$ relaxation times.

\section{RESULTS}

HI changes in MR images. In sham controls, $T_{1}$ in brain was similar in both hemispheres and was inversely dependent on age. $\mathrm{T}_{1}$ in the cerebral cortex was $21 \%$ shorter in 4 -wk-old than in 1 -wk-old animals $(p<0.01$; Table 1). Despite differences in initial $T_{1}$, the effect of cerebral $\mathrm{HI}$ on changes in $\mathrm{T}_{1}$ was similar in both age groups (Figs. 1 and 2, Table 1). During $\mathrm{HI}$, the ipsilateral hemisphere appeared bright and there were increases in the $T_{1}$ acquired from the ipsilateral compared with contralateral cortex $(p<0.01$; Figs. 1 and 2, Table 1). At 1 or 
Table 1. Changes in MR tissue relaxation* during and after an episode of cerebral HI in 1- and 4-wk-old rats

\begin{tabular}{|c|c|c|c|c|c|c|c|}
\hline & & \multicolumn{3}{|c|}{ 1-wk-old } & \multicolumn{3}{|c|}{ 4-wk-old } \\
\hline & & $\mathrm{T}_{1}(\mathrm{~ms})$ & $\mathrm{T}_{2}(\mathrm{~ms})$ & water $(\%)$ & $\mathrm{T}_{1}(\mathrm{~ms})$ & $\mathrm{T}_{2}(\mathrm{~ms})$ & water $(\%)$ \\
\hline Sham & Contralateral & $2627 \pm 83$ & $64 \pm 3$ & $88.3 \pm 0.4$ & $2080 \pm 66$ & $46 \pm 3$ & $81.1 \pm 0.4$ \\
\hline \multirow[t]{2}{*}{ During HI } & Contralateral & $2729 \pm 167$ & $61 \pm 5$ & $88.3 \pm 0.2$ & $2064 \pm 77$ & $46 \pm 3$ & $81.4 \pm 0.5$ \\
\hline & Ipsilateral & $2923 \pm 169 \ddagger$ & $80 \pm 4 \ddagger$ & $88.9 \pm 0.2 \ddagger$ & $2358 \pm 103 t$ & $47 \pm 3$ & $82.3 \pm 0.4 \ddagger$ \\
\hline \multirow[t]{2}{*}{$1 \mathrm{~h}$ after $\mathrm{HI}$} & Contralateral & $2757 \pm 190$ & $64 \pm 5$ & $88.5 \pm 0.2$ & $2143 \pm 87$ & $49 \pm 2$ & $81.4 \pm 0.3$ \\
\hline & Ipsilateral & $2993 \pm 149 \dagger$ & $78 \pm 7+$ & $89.2 \pm 0.3+$ & $2237 \pm 97 \dagger$ & $50 \pm 2$ & $82.1 \pm 0.3+$ \\
\hline $24 \mathrm{~h}$ after $\mathrm{HI}$ & Ipsilateral & $3007 \pm 200 \dagger$ & $100 \pm 20 \%$ & $89.4 \pm 0.5 \dagger$ & $2195 \pm 149 \dagger$ & $55 \pm 6 \dagger$ & $82.2 \pm 0.6 \dagger$ \\
\hline
\end{tabular}

* $\mathrm{T}_{1}$ and $\mathrm{T}_{2}$ in the cortex were measured from MR imaging maps of $\mathrm{T}_{1}$ and $\mathrm{T}_{2}$. Water content in the cerebrum was measured using dry-wet weight of tissue presented as a $\%$ of the wet weight of tissue.

$\dagger p<0.05, \ddagger p<0.01 \mathrm{vs}$ the contralateral cortex, paired $t$ test.

\section{before \\ during \\ $1 \mathrm{~h}$ \\ 24h}

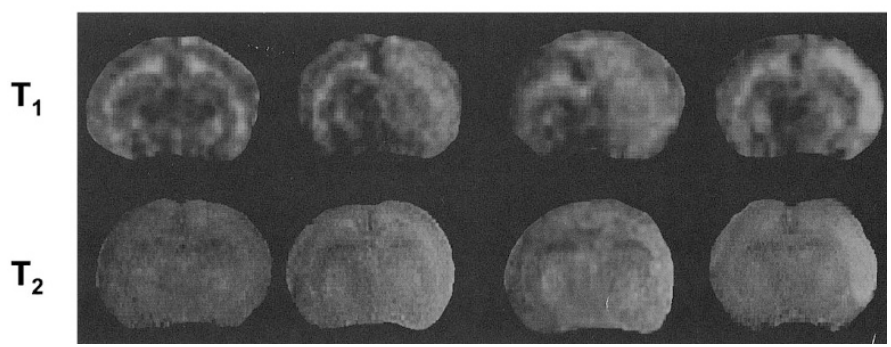

Figure 1. $\mathrm{T}_{1}$ - and $\mathrm{T}_{2}$-weighted images in 1-wk-old rats obtained before $\mathrm{HI}$ during HI, and at 1 or $24 \mathrm{~h}$ after HI. Areas of HI injury appear bright within the hemisphere ipsilateral to the right carotid artery occlusion.

\section{before} during

$1 \mathrm{~h}$ 24h

$\mathbf{T}_{1}$

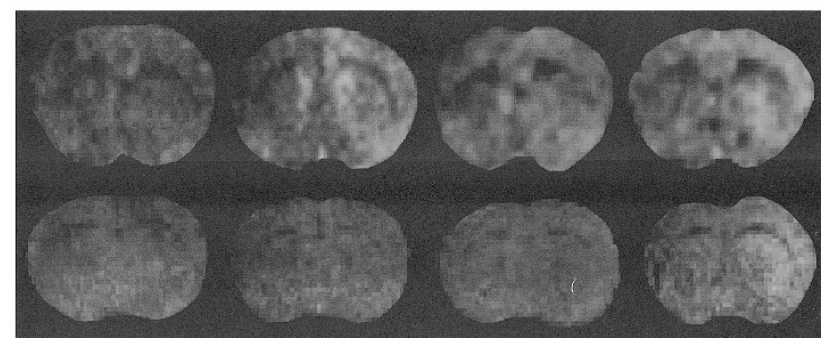

Figure 2. $\mathrm{T}_{1}$ - and $\mathrm{T}_{2}$-weighted images in 4-wk-old rats obtained before $\mathrm{HI}$, during HI, and at 1 or $24 \mathrm{~h}$ after HI. Areas of HI injury appear bright within the hemisphere ipsilateral to the right carotid artery occlusion.

$24 \mathrm{~h}$ after the termination of $\mathrm{HI}, \mathrm{T}_{1}$ from the ipsilateral cortex remained elevated in both age groups $(p<0.05)$.

In sham controls, $T_{2}$ in the rat brain was similar in both hemispheres and also inversely dependent on age. $\mathrm{T}_{2}$ in the cerebral cortex was $28 \%$ shorter in 4 -wk-old than in 1 -wk-old animals $(p<0.01$; Table 1). In addition, the time course of HI changes in $\mathrm{T}_{2}$ differed in young and older rats (Figs. 1 and 2, Table 1). During HI, the ipsilateral hemisphere appeared bright, and there were increases in $\mathrm{T}_{2}$ in the ipsilateral cerebral cortex in 1-wk-old $(p<0.01)$ but not in 4-wk-old animals. In the 1-wk-olds, the elevations in $\mathrm{T}_{2}$ remained at $1 \mathrm{~h}$, increasing further at $24 \mathrm{~h}$ after the end of $\mathrm{HI}(p<0.01)$. In the 4-wk-olds, increases in $\mathrm{T}_{2}$ ipsilaterally were detected only at $24 \mathrm{~h}$ after the end of HI $(p<0.05)$.

In sham controls, cerebral proton density was similar in both hemispheres but decreased with age. Proton density in the cerebral cortex was 7\% less in 4-wk-old than in 1-wk-old animals $(p<0.05)$. No ipsilateral-contralateral differences in proton-density were observed during or after HI.

HI changes in water content. In sham controls, brain water content assessed with wet-dry weight differences was similar in both hemispheres and inversely dependent on age. Water content in the forebrain was $8 \%$ lower in 4 -wk-old than in 1 -wk-old animals $(p<0.01$; Table 1$)$. The time course of HI changes in water content was similar in both age groups (Table 1). During HI, the water content acquired from the ipsilateral compared with the contralateral hemisphere became elevated $(p<0.01)$ and remained elevated in both age groups at 1 or $24 \mathrm{~h}$ after the termination of HI $(p<0.05)$.

Correlation of MR relaxation times with water content. Using a regression analysis, a linear relationship was demonstrated to be present between the $\mathrm{T}_{1}$ and brain water measurements obtained under control and HI conditions $\left(r^{2}=0.74, p\right.$ $=0.00008$ for the 1 -wk-old rats; $r^{2}=0.70, p=0.0003$ for the 4-wk-old rats; Fig. 3). In contrast, the regression analysis for the $\mathrm{T}_{2}$ data demonstrated a difference between age groups with the correlation between $\mathrm{T}_{2}$ and water content being higher in 1-wk-old than 4-wk-old animals $\left(r^{2}=0.68, p=0.001\right.$ for the 1-wk-old rats; $r^{2}=0.45, p=0.04$ for the 4-wk-old rats; Fig. $3)$.

Whether changes in water content are reflected better by changes in $T_{1}$ or $T_{2}$ was examined by comparing the changes in the ratios of ipsilateral to contralateral water content and MR relaxation times during the time course of cerebral HI (Figs. 4 and 5). There was a good correspondence between changes in water content and either $T_{1}$ or $T_{2}$, except for in 4-wk-old rats, in which there was a discrepancy during and $1 \mathrm{~h}$ after $\mathrm{HI}$ at which times water content increased despite an absence of changes in $T_{2}$.

\section{DISCUSSION}

The present study demonstrates that $\mathrm{T}_{1}$ and $\mathrm{T}_{2}$ maps detect differentially the brain water changes associated with a cerebral $\mathrm{HI}$ insult and indicate that there are differences in the cerebral edema evolving after $\mathrm{HI}$ in immature compared with more mature brain. There are early changes in water content associated with cerebral $\mathrm{HI}$ that are similar in immature and older brain, and $\mathrm{T}_{1}$ maps or inversion recovery-weighted images are able to detect such changes. In contrast, as has been reported in adult brain (20), in young juvenile rats, $T_{2}$ changes occur in 


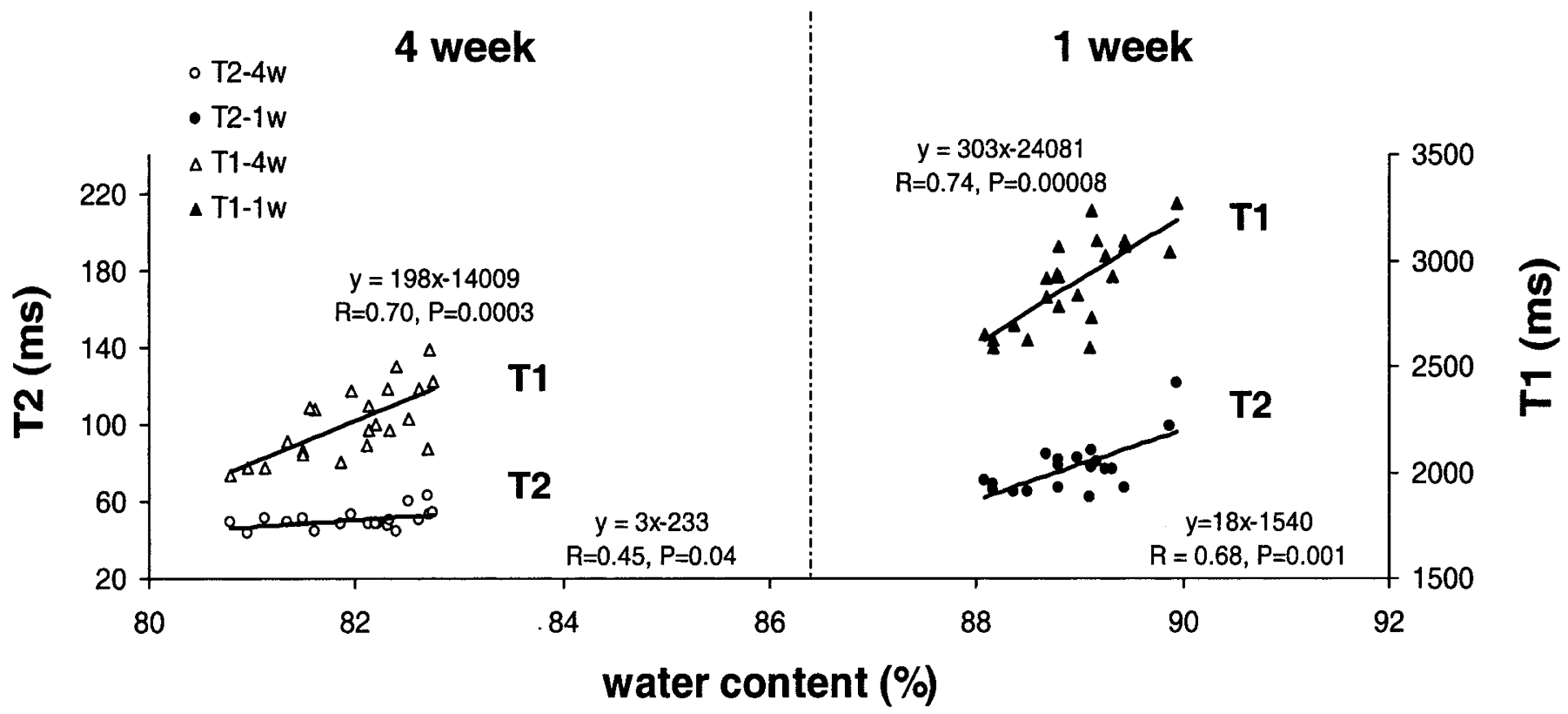

Figure 3. Correlation of $\mathrm{T}_{1}$ and $\mathrm{T}_{2}$ relaxation times with water content (wet-dry weight) in the hemisphere ipsilateral to the occlusion in control and $\mathrm{HI}$ rats (from the start of $\mathrm{HI}$ to $24 \mathrm{~h}$ after $\mathrm{HI}$ ) in 1- and 4-wk-old rats.

1 week

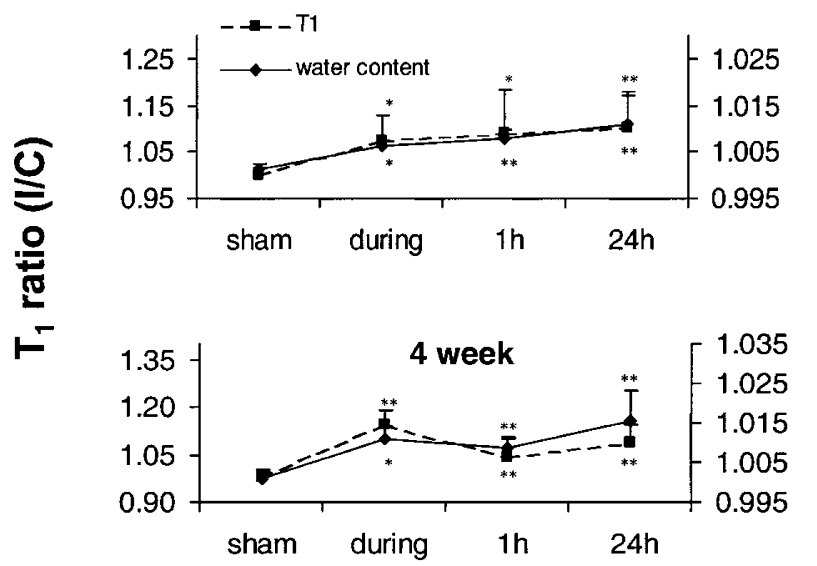

Figure 4. Changes in $T_{1}$ relaxation times and water content during the time course of an $\mathrm{HI}$ insult in 1- and 4-wk-old rat brain. Shown are mean ratios for $\mathrm{T}_{1}$ and water content acquired from the hemisphere ipsilateral $(I)$ vs contralateral $(C)$ to the right carotid artery occlusion in sham controls or in HI rats during and at 1 or $24 \mathrm{~h}$ after HI. Data are displayed as mean $\pm \mathrm{SD} . * * p<0.01$, $* p<0.05$ vs sham controls.

areas of edema or infarction only hours to days after an ischemic insult, whereas such changes appear much earlier, already during $\mathrm{HI}$, in neonatal brain. Indeed $\mathrm{T}_{2}$ appears to detect the cerebral edema that is accompanied by BBB disruption, presumably reflecting changes in the physicochemical properties of water and its environment rather than total water content alone (13).

The ability of $\mathrm{T}_{1}$ imaging methods to readily detect the edema associated with cerebral ischemia appears to be dependent on a number of factors. The use of standard $\mathrm{T}_{1}$ spin-echoweighted imaging in stroke patients has been rather insensitive for detecting abnormalities within the brain at an acute stage of cerebral ischemia (21-24). In contrast, in experimental animals, quantitative increases in $T_{1}$ comparable to those in the
1 week

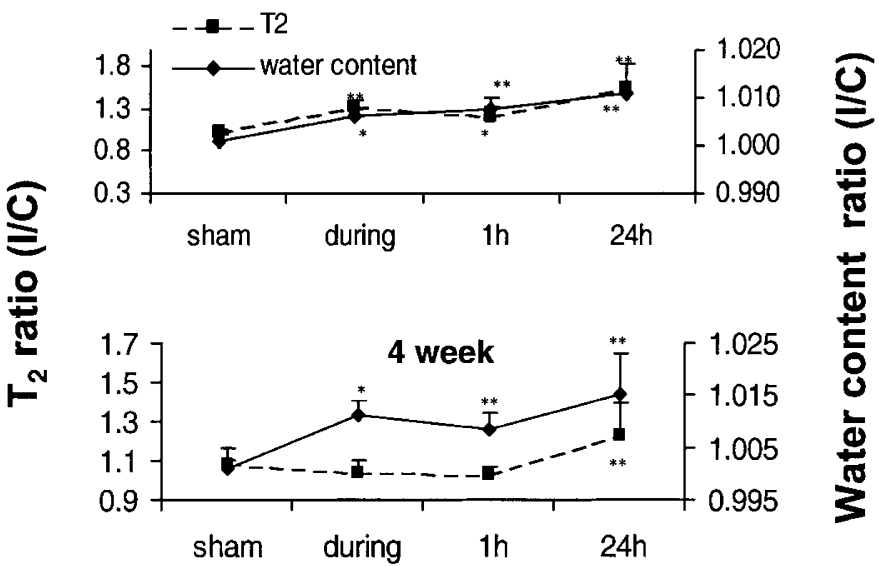

Figure 5. Changes in $T_{2}$ relaxation times and water content during the time course of an HI insult in 1- and 4-wk-old rat brain. Shown are mean ratios for $\mathrm{T}_{2}$ and water content acquired from the hemisphere ipsilateral $(I)$ vs contralateral $(C)$ to the right carotid artery occlusion in sham controls or in HI rats during and at 1 or $24 \mathrm{~h}$ after HI. Data are displayed as mean \pm SD. $* * p<0.01$, $* p<0.05$ vs sham controls.

present study have been observed within minutes to a few hours after focal cerebral ischemia $(2,25,26)$. Although some of the initial increase in $\mathrm{T}_{1}$ (up to $2 \%$ ) could be caused by reductions in cerebral blood flow during HI $(25,26)$, the majority of the acute increases in $\mathrm{T}_{1}$ during and after $\mathrm{HI}$, which ranged from 7 to $14 \%$, likely are related to the increased water content measured in the tissue. One obvious difference between experimental and clinical studies is in the MR sequences used to acquire $T_{1}$ images. Inversion-recovery $T_{1}$-weighted images or $T_{1}$ maps rather than spin-echo $T_{1}$-weighted images are often used in animals, in which the former can be more sensitive for detecting edema. Animal MR imaging is also usually performed at higher field, in which the changes in $T_{1}$ associated 
with focal ischemia are greater than at low field (e.g. 4.7 or 9.4 $\mathrm{T}$ versus $1.5 \mathrm{~T}$, respectively) $(25,27)$. As high-field clinical magnets and faster $T_{1}$ acquisition sequences become more widely available, quantitative $T_{1}$ imaging could prove beneficial for diagnosing the acute edema associated with $\mathrm{HI}$ or stroke clinically (28).

The present study found a good correlation between HI changes in brain water and $T_{1}$. Previous studies correlating $T_{1}$ or $\mathrm{T}_{2}$ with water content have observed a rather narrow range of water content changes, some being maximal many hours after cerebral ischemia $(3-7,29,30)$. In these studies a range of insignificant to highly significant correlations between $T_{2}$ and water content have been reported. Presently, water content varied widely ( 81 to $90 \%$ ) between control animals and after HI. The comparison of edema and MR changes resulted in a good temporal agreement between changes in $T_{2}$ and water content during the time course of $\mathrm{HI}$ in the 1-wk-old brain but only a partial agreement in the 4-wk-olds. The rather poor overall correlation between $T_{2}$ and brain water content in 4-wk-olds contrasts with the highly significant correlation between $T_{1}$ and brain water content at either age. This is similar to the better correlation of $T_{1}$ than $T_{2}$ with changes in water content induced by triethyltin intoxication or cold-injury $(8,9)$. This suggests that changes in $T_{1}$ are an indicator of alterations in the total amount of water, irrespective of ontogenic differences in the tissue, including cell density, cell composition, BBB permeability, the distribution of bound versus free water, or whether the edematous fluid is enriched with proteins or electrolytes (13, 31, 32).

Proton-density imaging was able to detect the rather large $(8 \%)$ ontogenic decreases in water content but not the smaller $\mathrm{HI}$ increases in water content. A large variability is inherent in the proton-density measurements made using $\mathrm{T}_{1}$ (33), resulting in SDs of 3 to $7 \%$. However, even smaller SDs of $\pm 1.5 \%$ from proton-density measurements made using spectroscopic methods might be too large for routine determination of cerebral edema (33).

The greatest difference in the HI changes between $T_{1}$ and $T_{2}$ ratios occurred in 4-wk-old animals in which there was an increase in $T_{1}$ and brain water but no change in $T_{2}$ during and immediately after $\mathrm{HI}$. The reason for this is uncertain, but it is possible that protein extravasation influences the $T_{2}$ obtained (13). Also to be considered are an interaction between endogenous macromolecules and water molecules or changes in the bound and free fractions of water (34). Multicomponent analysis of the fitting curve of $T_{2}$ relaxation decay has demonstrated that $\mathrm{T}_{2}$ can be separated into at least two components in which the fast $T_{2}$ likely represents the fraction of water bound to macromolecules, which is predominant in the intracellular compartment, whereas the slow $\mathrm{T}_{2}$ represents free water, which exists primarily in the extracellular compartment $(8,9,32)$. Indeed, the fraction of bound water increases as the brain matures, being associated with ontogenic decreases in extracellular space $(31,32,35)$. Furthermore, the patterns of changes in fast $T_{2}$ and slow $T_{2}$ have been observed to differ greatly in brain edema induced by ischemia or trauma $(9,36)$. Unfortunately, in our study the echo time of $20 \mathrm{~ms}$ was much longer than the minimum that has been suggested for the analysis of the short component of $\mathrm{T}_{2}$ in the brain, and eight echoes is considered insufficient for an accurate multiexponential fitting of the $T_{2}$ data (37). Thus, additional studies with an appropriate selection of MR acquisition variables are needed to analyze the dynamic distribution of slow and fast components of $\mathrm{T}_{2}$ during and after $\mathrm{HI}$.

\section{CONCLUSIONS}

In summary, there are ontogenic changes in brain water content and age-dependent differences in the edematous changes observed in response to an $\mathrm{HI}$ insult. By investigating the relationship between changes in cerebral $T_{1}$ and $T_{2}$ with alterations in brain water content in rats at different ages, we have demonstrated that changes in $T_{1}$ but not $T_{2}$ best serve as an indicator of edema associated with an elevation in water content. Changes in $T_{2}$ appear to best reflect the vasogenic edema associated with cerebral HI.

Acknowledgments. The authors thank Saro Bascaramurty, Tadeusz Foniok, and Eilean McKenzie for their excellent technical assistance.

\section{REFERENCES}

1. Huppi PS 2002 Advances in postnatal neuroimaging: relevance to pathogenesis and treatment of brain injury. Clin Perinatol 29:827-856

2. Knight RA, Dereski MO, Helpern JA, Ordidge RJ, Chopp M 1994 Magnetic resonance imaging assessment of evolving focal cerebral ischemia: comparison with histopathology in rats. Stroke 25:1252-1261

3. Boxt LM, Hsu D, Katz J, Detweiler P, Mclaughlin S, Kolb TJ, Spotnitz HM 1993 Estimation of myocardial water content using transverse relaxation time from dual spin-echo magnetic resonance imaging. Magn Reson Imaging 11:375-383

4. Kamman RL, Go KG, Brouwer W, Berendsen HJ 1988 Nuclear magnetic resonance relaxation in experimental brain edema: effects of water concentration, protein concentration, and temperature. Magn Reson Med 6:265-274

5. Kiricuta Jr IC, Simplaceanu V 1975 Tissue water content and nuclear magnetic resonance in normal and tumor tissues. Cancer Res 35:1164-1167

6. Shioya S, Haida M, Tsuji C, Ono Y, Miyairi A, Fukuzaki M, Ohta Y, Yamabayashi $\mathrm{H} 1990 \mathrm{~T}_{2}$ of endotoxin lung injury with and without methylprednisolone treatment. Magn Reson Med 15:201-210

7. Fried R, Boxt LM, Miller III RH, Marx M, Aronovitz M, Reid LM, Adams DF 1986 Nuclear magnetic resonance spectroscopy of rat ventricles following supravalvar aortic banding: a model of left ventricular hypertrophy. Invest Radiol 21:622-625

8. Barnes D, Mcdonald WI, Johnson G, Tofts PS, Landon DN 1987 Quantitative nuclear magnetic resonance imaging: characterisation of experimental cerebral oedema. J Neurol Neurosurg Psychiatry 50:125-133

9. Naruse S, Horikawa Y, Tanaka C, Hirakawa K, Nishikawa H, Yoshizaki K 1982 Proton nuclear magnetic resonance studies on brain edema. J Neurosurg 56:747-752

10. Lorenzo AV, Jolesz FA, Wallman JK, Ruenzel PW 1989 Proton magnetic resonance studies of triethyltin-induced edema during perinatal brain development in rabbits. J Neurosurg 70:432-440

11. McArdle CB, Richardson CJ, Hayden CK, Nicholas DA, Amparo EG 1987 Abnormalities of the neonatal brain: MR imaging. Part II. Hypoxic-ischemic brain injury. Radiology 163:395-403

12. Masumura M 1987 Proton relaxation time of immature brain. I. Measurement of proton relaxation time $\left(\mathrm{T}_{1}\right.$ and $\left.\mathrm{T}_{2}\right)$ in immature rat brain by ${ }^{1} \mathrm{H}-\mathrm{NMR}$ spectroscopy. Childs Nerv Syst 3:2-5

13. Qiao M, Malisza KL, Del Bigio MR, Tuor UI 2001 Correlation of cerebral hypoxicischemic $\mathrm{T}_{2}$ changes with tissue alterations in water content and protein extravasation. Stroke 32:958-963

14. Jacobson S 1963 Sequence of myelinization in the brain of the albino rat. A. Cerebral cortex, thalamus and related structures. J Comp Neurol 121:5-29

15. Qiao M, Malisza KL, Del Bigio MR, Tuor UI 2002 Transient hypoxia-ischemia in rats: changes in diffusion-sensitive MR imaging findings, extracellular space, and $\mathrm{Na}^{+}-\mathrm{K}^{+}$-adenosine triphosphatase and cytochrome oxidase activity. Radiology 223:65-75

16. Siesjo BK 1978 Ischemia. In: Siesjo BK (ed) Brain Energy Metabolism. Wiley, New York, pp 453-588

17. Tuor UI, Del Bigio MR, Chumas PD 1996 Brain damage due to cerebral hypoxiaischemia in the neonate: pathology and pharmacological modification. Cerebrovase Brain Metab Rev 8:159-193

18. Wehrli FW, Breger RK, MacFall JR, Daniels DL, Haughton VM, Charles HC, Williams AL 1985 Quantification of contrast in clinical MR brain imaging at high magnetic field. Invest Radiol 20:360-369 
19. Mark J, Dai G, Xiang B, Sun J, Lazarow N, Lindsay WG, Corne R, Deslauriers R, Tian G 2002 Simultaneously monitoring both $\mathrm{T}(1)$ and $\mathrm{T}(2) *$ signal intensities on a bolus injection of Gd-DTPA may distinguish infarcted myocardium. J Magn Reson Imaging 15:532-540

20. Loubinoux I, Volk A, Borredon J, Guirimand S, Tiffon B, Seylaz J 1997 Spreading of vasogenic edema and cytotoxic edema assessed by quantitative diffusion and $\mathrm{T}_{2}$ magnetic resonance imaging. Stroke 28:419-426

21. Geijer B, Brockstedt S, Lindgren A, Stahlberg F, Norrving B, Holtas S 1999 Radiological diagnosis of acute stroke: comparison of conventional MR imaging, echo-planar diffusion-weighted imaging, and spin-echo diffusion-weighted imaging. Acta Radiol 40:255-262

22. Gonzalez RG, Schaefer PW, Buonanno FS, Schwamm LH, Budzik RF, Rordorf G, Wang B, Sorensen AG, Koroshetz WJ 1999 Diffusion-weighted MR imaging: diagnostic accuracy in patients imaged within 6 hours of stroke symptom onset. Radiology 210:155-162

23. Shimosegawa E, Inugami A, Okudera T, Hatazawa J, Ogawa T, Fujita H, Toyoshima H, Uemura K 1993 Embolic cerebral infarction: MR findings in the first 3 hours after onset. AJR Am J Roentgenol 160:1077-1082

24. Yuh WT, Crain MR, Loes DJ, Greene GM, Ryals TJ, Sato Y 1991 MR imaging of cerebral ischemia: findings in the first 24 hours. AJNR Am J Neuroradiol $12: 621-629$

25. Kettunen MI, Grohn OHJ, Lukkarinen JA, Vainio P, Silvennoinen MJ, Kauppinen RA 2000 Interrelations of T-1 and diffusion of water in acute cerebral ischemia of the rat. Magn Reson Med 44:833-839

26. Calamante F, Lythgoe MF, Pell GS, Thomas DL, King MD, Busza AL, Sotak CH, Williams SR, Ordidge RJ, Gadian DG 1999 Early changes in water diffusion, perfusion, $\mathrm{T}_{1}$, and $\mathrm{T}_{2}$ during focal cerebral ischemia in the rat studied at $8.5 \mathrm{~T}$. Magn Reson Med 41:479-485
27. Crooks LE, Arakawa M, Hoenninger J, McCarten B, Watts J, Kaufman L 1984 Magnetic resonance imaging: effects of magnetic field strength. Radiology 151:127-133

28. Deoni SC, Rutt BK, Peters TM 2003 Rapid combined $T_{1}$ and $T_{2}$ mapping using gradient recalled acquisition in the steady state. Magn Reson Med 49:515-526

29. Estilaei M, MacKay A, Whittall K, Mayo J 1999 In vitro measurements of water content and $\mathrm{T}_{2}$ relaxation times in lung using a clinical MRI scanner. J Magn Reson Imaging 9:699-703

30. Lin W, Paczynski RP, Venkatesan R, He YY, Powers WJ, Hsu CY, Haacke EM 1997 Quantitative regional brain water measurement with magnetic resonance imaging in a focal ischemia model. Magn Reson Med 38:303-310

31. Furuse M, Gonda T, Inao S, Kuchiwaki H, Hirai N, Kageyama N 1987 Thermal analysis on water components in brain tissue- quantitative determination of free and bound water fractions. No To Shinkei 39:761-767

32. Sulyok E, Nyul Z, Bogner P, Berenyi E, Repa I, Vajda Z, Doczi T, Sedin G 2001 Brain water and proton magnetic resonance relaxation in preterm and term rabbit pups: their relation to tissue hyaluronan. Biol Neonate 79:67-72

33. Ernst T, Kreis R, Ross BD 1993 Absolute quantitation of water and metabolites in the human brain. I. Compartments and water. J Magn Reson Series B 102:1-8

34. Mathur-De VR 1984 Biomedical implications of the relaxation behaviour of water related to NMR imaging. Br J Radiol 57:955-976

35. Vorisek I, Sykova E 1997 Ischemia-induced changes in the extracellular space diffusion parameters, $\mathrm{K}^{+}$, and $\mathrm{pH}$ in the developing rat cortex and corpus callosum. J Cereb Blood Flow Metab 17:191-203

36. Horikawa Y, Naruse S, Tanaka C, Hirakawa K, Nishikawa H 1986 Proton NMR relaxation times in ischemic brain edema. Stroke 17:1149-1152

37. Graham SJ, Stanchev PL, Bronskill MJ 1996 Criteria for analysis of multicomponen tissue $\mathrm{T}_{2}$ relaxation data. Magn Reson Med 35:370-378 